\title{
Saikosaponins induced hepatotoxicity in mice via lipid metabolism dysregulation and oxidative stress: a proteomic study
}

\author{
Xiaoyu Li ${ }^{1 \dagger}$, Xiaojiaoyang Li, ${ }^{2,3 \dagger}$, Junxian Lu', Youyi Huang ${ }^{1}$, Lili LV1, Yongfu Luan', Runping Liu ${ }^{3 *}$ and Rong Sun ${ }^{1,4,5^{*}}$
}

\begin{abstract}
Background: Radix Bupleuri (RB) has been popularly used for treating many liver diseases such as chronic hepatic inflammation and viral Hepatitis in China. Increasing clinical and experimental evidence indicates the potential hepatotoxicity of RB or prescriptions containing RB. Recently, Saikosaponins (SS) have been identified as major bioactive compounds isolated from $\mathrm{RB}$, which may be also responsible for RB-induced liver injury.

Methods: Serum AST, ALT and LDH levels were determined to evaluate SS-induced liver injury in mice. Serum and liver total triglyceride and cholesterol were used to indicate lipid metabolism homeostasis. Liver ROS, GSH, MDA and iNOS were used to examine the oxidative stress level after SS administration. Western blot was used to detect CYP2E1 expression. A 8-Plex iTRAQ Labeling Coupled with 2D LC - MS/MS technique was applied to analyze the protein expression profiles in livers of mice administered with different doses of SS for different time periods. Gene ontology analysis, cluster and enrichment analysis were employed to elucidate potential mechanism involved. HepG2 cells were used to identify our findings in vitro.

Results: SS dose- and time-dependently induced liver injury in mice, indicated by increased serum AST, ALT and LDH levels. According to proteomic analysis, 487 differentially expressed proteins were identified in mice administrated with different dose of SS for different time periods. Altered proteins were enriched in pathways such as lipid metabolism, protein metabolism, macro molecular transportation, cytoskeleton structure and response to stress. SS enhanced CYP2E1 expression in a time and dose dependent manner, and induced oxidative stress both in vivo and in vitro.

Conclusion: Our results identified hepatotoxicity and established dose-time course-liver toxicity relationship in mice model of SS administration and suggested potential mechanisms, including impaired lipid and protein metabolism and oxidative stress. The current study provides experimental evidence for clinical safe use of RB, and also new insights into understanding the mechanism by which SS and RB induced liver injury.
\end{abstract}

\section{Background}

Radix Bupleuri (RB) is the dry root of Bupleurum chinense DC. (Apiaceae) and Bupleurum scorzonerifolium Willd. It represents one of the most successful herbal drugs in China and other Asian countries and has been widely used as a treatment for many diseases over the past 2000 years. It has effects on cold fever, chill and fever in

\footnotetext{
* Correspondence: runping.liu@vcuhealth.org; runping.liu@hotmail.com; sunrongsatcm@hotmail.com

†Equal contributors

${ }^{3}$ Department of Microbiology and Immunology, Virginia Commonwealth University, Richmond, VA 23220, USA

${ }^{1}$ Department of Medical Pathomorphology, Shandong Academy of

Traditional Chinese Medicine, Jinan 250014, Shandong, China

Full list of author information is available at the end of the article
}

turn, the feeling of oppression and illness in the chest and hypochondria [1, 2]. Furthermore, RB has been popularly used to treat many liver diseases such as chronic hepatic inflammation and viral hepatitis [3]. The widely prescribed Chinese herbal product, Xiao-Chai-Hu-Tang, a famous multi-herbal remedy containing $\mathrm{RB}$, is renowned for its possible healing effects on chronic hepatitis $B$ and its beneficial effects on preventing the development of hepatocellular carcinoma in patients with liver cirrhosis [4-6]. A study performed in Hong Kong has shown that 39\% patients with chronic liver diseases prefer to use Chinese herbal products and $21 \%$ and $13 \%$ patients have taken Traditional Chinese Medicine (TCM) previously or are currently using TCM to improve their liver conditions, 
respectively [7]. According to the Chinese pharmacopoeia, the clinical safe dosage of $\mathrm{RB}$ prescriptions ranged from $3 \mathrm{~g} /$ day to $10 \mathrm{~g} /$ day, based on $70 \mathrm{~kg}$ body weight. However, based on accumulating evidence, RB probably contributes to hepatotoxicity, particularly overdose-induced acute liver injury and accumulation-related hepatotoxicity [8-11]. Patients using Xiao-Chai-Hu-Tang and LongDan-Xie-Gan-Tang or Chinese herbal products containing more than $19 \mathrm{~g}$ of $\mathrm{RB}$ might were recently shown to have an increased risks of liver injury [3]. Based on consecutive reports of the adverse hepatotoxic effects of RB, increasing concerns about its effectiveness and safety have been raised.

Saikosaponins (SS) are oleanane type triterpenoid saponins, and are the major bioactive compounds isolated from RB [12]. SS exhibits anti-inflammatory, anti-tumor, anti-viral, immunoregulatory and hepatoprotective effects [13]. Our previous study demonstrated that SS contributes to RB-induced chronic and acute hepatotoxic effects on rats and mice [14-17]. A statistically significant linear time- and dose-dependent trends for SS-induced liver toxicity were identified [14]. However, the molecular mechanisms underlying the hepatotoxicity of SS and its molecular targets are still unclear.

Proteomic technologies are large-scale research tools that provide abundant data regarding protein expression patterns, and are widely used to explore the molecular mechanisms of complex bioactive mixtures, including TCM. Classical 2DE has been commonly used for liver injury proteomics, but drawbacks have also been noted, such as low sensitivity, the extensive time required to complete procedure, and for the failure to detect lowabundance proteins $[18,19]$. Recently, a new method, iTRAQ labelling coupled with LC-MS/MS, which is more sensitive, automatic, and multidimensional, has been applied to detect a large range of molecules $(>20 \mathrm{kDa})$ and is more suitable for the study of pathogenic mechanisms and pathophysiology of diseases [20, 21].

In the current study, the liver toxicity of SS was first identified using a histopathologic evaluation and serum biochemistry assays. The iTRAQ proteomic technology was then employed to study the expression of SSregulated proteins in the mouse liver. The identification of these differentially expressed proteins not only revealed time- and dose-related patterns of SS-induced hepatotoxicity but also candidate protein targets and signaling pathways, which provide novel insights into the underlying mechanism.

\section{Methods}

\section{Preparation of SS from RB}

In accordance with Chinese pharmacopoeia, and GMP standards, RB was purchased from Shandong Baiweitang
(Jinan, Shandong), and authenticated by Professor Lin Hui-bin, Shandong Academy of TCM. The method used to prepare an alcohol extract of Bupleurum SS is described below: The samples were first extracted with $65 \%$ alcohol; the prepared extract was then recovered with alcohol and concentrated. Following purification on a D101 macroporous resin column, the $70 \%$ alcohol extract of the concentrated solution was collected. The crude drug content was $12.0 \mathrm{~g} / \mathrm{mL}$ and the total SS content was $972.8 \mathrm{mg} / \mathrm{mL}$. After the extract was air-dried under reduced pressure, the samples were diluted to the required concentration in a suspension with saline for animal expreiments, or phosphates buffered saline (PBS) for in vitro experiments.

\section{Phytochemical analysis of the extracts}

Saikosaponins were prepared for High Performance Liquid Chromatography (HPLC) analysis by filtering through $0.45 \mu \mathrm{M}$ membrane. Sakosaponin A (SSa) and Saikosaponin D (SSd) were separated on a Thermo Synecrosis C18 column (5 mm, $4.6 \mathrm{~mm} \times 250 \mathrm{~mm})$. SHIMADZU LC-20AT equipped with UV/VIS detector was used. The mobile phase consists of two solvents: Acetonitrile (A) and water (B). The following gradient programs were set: from $25 \% \mathrm{~A}$ to $90 \% \mathrm{~A}$ in $50 \mathrm{~min}$ and $90 \%$ A for $5 \mathrm{~min}$. The detection wavelength was set to $210 \mathrm{~nm}$.

\section{Animals and study design}

Kunming mice weighing $(20 \pm 2) \mathrm{g}$ of both sexes were purchased from the Experimental Animal Breeding and Research Center, Shandong University ([SCXK (Lu)20,090,001]). The mice were then housed in cages by gender under conditions of constant humidity $(55 \pm 5) \%$, temperature $(22 \pm 2){ }^{\circ} \mathrm{C}$, a $12 \mathrm{~h}$ light/dark cycle and water ad libitum. All animal experiments were conducted in accordance with institutional guidelines and ethics.

For the time-toxicity study, 80 mice were divided into 7 groups including $0,1,2,4,8,12,24$ and 48 h groups. The mice were intragastrically administered with saline (vehicle control) or SS at dosage of $21.650 \mathrm{~g} / \mathrm{kg}$ of body weight. For dose-toxicity study, 40 mice were divided into 5 groups and administrated different doses of SS for $24 \mathrm{~h}$, including saline (vehicle control), VL (4.675 g/ $\mathrm{kg}$ of body weight), L (7.925 g/kg), M (12.957 g/ kg), H $(21.650 \mathrm{~g} / \mathrm{kg})$ and $\mathrm{VH}(36.075 \mathrm{~g} / \mathrm{kg})$ groups. At the end of the treatment, the mice were sacrificed and livers were collected. Protein concentrations were determined by BCA Protein Assay Kit (Beyotime Biotech, China). Blood was collected for biochemistry analysis. Serum levels of alanine aminotransferase (ALT), aspartate aminotransferase (AST), lactic acid dehydrogenase (LDH), total cholesterol and triglyceride (TG) were determined. 
All assay kits were purchased from Jiancheng Bioengineering Institute (China).

\section{iTRAQ labelling and 2D LC-MS/MS Analysis}

The iTRAQ labelling was performed according to the manufacturer's protocol (Applied Biosystem Inc., Foster city, CA). Briefly, $100 \mu \mathrm{g}$ of proteins were prepared with iTRAQ $^{\text {mo }}$ dissolution buffer (ABI, Foster City, USA). After reduction and alkylation, protein solutions were digested overnight with sequencing-grade modified trypsin (Sigma Co. USA). The peptides were then labelled with iTRAQ regents. The samples were desalted with Sep-Pak Vac C18 cartridges (Waters, Milford, MA) and dried in a vacuum concentrator.

The mixture of iTRAQ labelling peptides was fractionated by strong cation exchange (SCX) chromatography on a 20 AD HPLC system (Shimadzu; Kyoto, Japan) using a Polysulfoethyl column $(2.1 \times 100 \mathrm{~mm}, 5 \mu \mathrm{m}$, $200 \AA$, The Nest Group, Southborough, MA). The peptide mixtures were reconstituted in Buffer A $(10 \mathrm{mM}$ $\mathrm{KH}_{2} \mathrm{PO}_{4}$ in $25 \% \mathrm{ACN}$ (Fisher scientific, Fair Lawn, New Jersey)), loaded into the column and were separated at a flow rate of $200 \mu \mathrm{l} / \mathrm{min}$ for $60 \mathrm{~min}$ with a gradient of 0-80\% Buffer B (Buffer A containing $350 \mathrm{mM} \mathrm{KCl}$ ) in Buffer A. The absorbance at $214 \mathrm{~nm}$ and $280 \mathrm{~nm}$ was monitored and a total of 8 SCX fractions were collected. The fractions were vacuum dried and then resuspended in $50 \mu \mathrm{L}$ of HPLC Buffer A ( $5 \%$ ACN, $0.1 \%$ formic acid (TEDIA, Fairfield, USA)), loaded across the ZORBAX 300SB-C18 reversed-phase column $(5 \mu \mathrm{m}, 300 \AA$, $0.1 \times 150 \mathrm{~mm}$; Microm, Auburn, CA) and analyzed on a Triple Tof 5600 System (Applied Biosystem, USA) coupled with a 20 AD HPLC system (Shimadzu; Kyoto, Japan). The flow rate for elution was $0.3 \mu \mathrm{L} / \mathrm{min}$ using a $5 \%-35 \%$ gradient of HPLC Buffer B (95\% ACN, 0.1\% formic acid) for $120 \mathrm{~min}$. The survey scans were obtained with $\mathrm{m} / \mathrm{z}$ ranges of $400-1500$, for MS with up to four precursors were selected from the $\mathrm{m} / \mathrm{z}$ 100-2000 region for MS/MS.

\section{Proteomic data analysis and bioinformatics}

The MS data were extracted and searched against the Swiss Prot database $(20,090,303$ released) using the ProteinPilot software (Applied Biosystem, USA) to identify and quantify the peptides and proteins. The Paragon Algorithm and the Pro Group trypsin lgorithm (Applied Biosystem, USA) were sequentially applied to determine the final identification of the proteins. Autobias was assessed using protein pilot to eliminate some differences caused by the experimental process. An unused ProtScore $>1.3$ and more than one peptide above the 95\% confidence interval were set as threshold for protein identification. False Discover Rate (FDR) for protein detection was calculated as FDR $=(2 \times$ reverse $) /$ (forward + reverse). The global FDR of the combined data was $1 \%$. The biological processes were annotated by Gene Ontology (GO) database and KEGG database and manually slimed. Toxigenomics analysis was conducted using Comparative Toxigenomics Database. Clustering and enrichment analyses were performed as described previously. [22].

\section{Redox status assessment}

GSH and GSSG assay kit (Beyotime Biotech, China), reactive oxygen species (ROS) assay kit, Maleic Dialdehyde (MDA) assay kit and iNOS assay kit (Jiancheng Biotech, China) were used to determine the oxidative stress level in liver or cell. All the results were normalized to protein concentrations for animal studies or normalized to cell numbers for in vitro experiments.

\section{Western Blot analysis}

Total cell lysate from liver tissue were prepared using RIPA buffer. The protein concentrations were determined using Bio-Rad protein assay kit. The protein expression levels of CYP2E1 and GAPDH in liver samples were determined by Western Blot using specific primary antibody (Santa Cruz, CA, USA), as described previously [23].
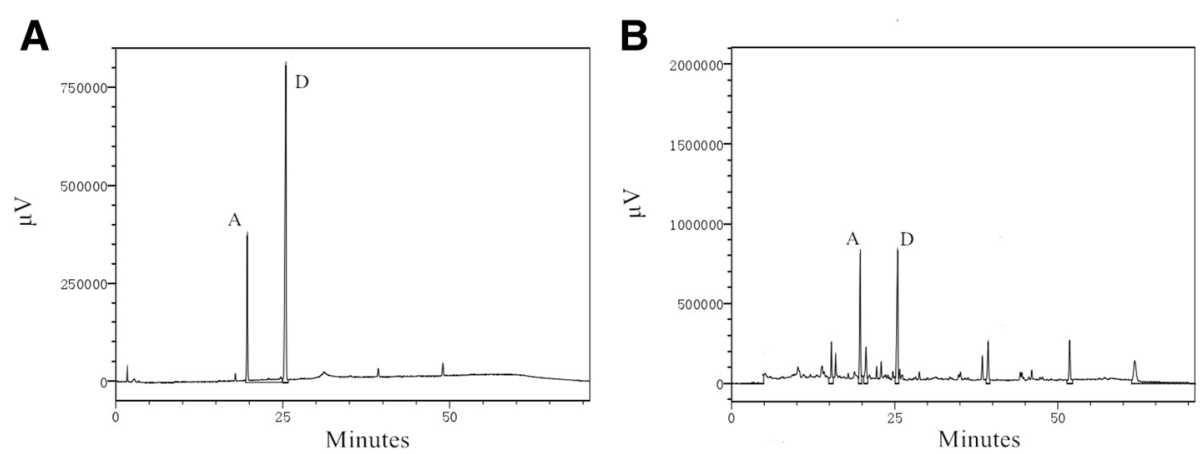

Fig. $1 \mathrm{HPLC}$ chromatograms. a Standard mix and b Alcohol elution of SS. SSa and SSd were indicated by "A" and "D", respectively 
Cell culture and cell experiment

HepG2 cell line was purchased from ATCC and were cultured in Dulbecco's modified Eagle's medium (DMEM) medium in supplement with $10 \%$ fetal bovine serum (FBS), penicillin $\mathrm{G}(100 \mathrm{U} / \mathrm{mL})$, streptomycin $(100 \mu \mathrm{g} / \mathrm{mL})$. All cell culture supplies were obtained from Gibco (Waltham, MA). HepG2 cells were treated with PBS (vehicle control) or different concentration of SS $(25 \mu \mathrm{g} / \mathrm{mL}, 50 \mu \mathrm{g} / \mathrm{mL}, 100 \mu \mathrm{g} /$ $\mathrm{mL}, 200 \mu \mathrm{g} / \mathrm{mL}$ and $400 \mu \mathrm{g} / \mathrm{mL}$ ) for $12 \mathrm{~h}$ or $24 \mathrm{~h}$. At the end of treatment, images of cells were taken. Cell viabilities were determined using Cell Counting Kit-8 (Dojindo, D.C. USA), according to manufacturer's instruction. Intracellular ROS, GSH levels and iNOS activity were determined, as described above (Method 2.6 Redox status assessment).

\section{Statistical analysis}

All the data are represented as Mean \pm SEM. One-way ANOVA and Dunnett's t-test were employed to analyze the differences between sets of data. A value of $P<0.05$ was considered statistically significant.
A

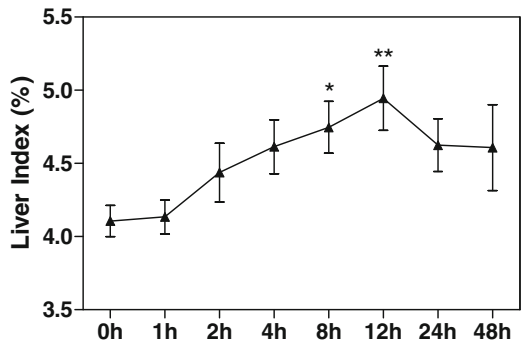

B

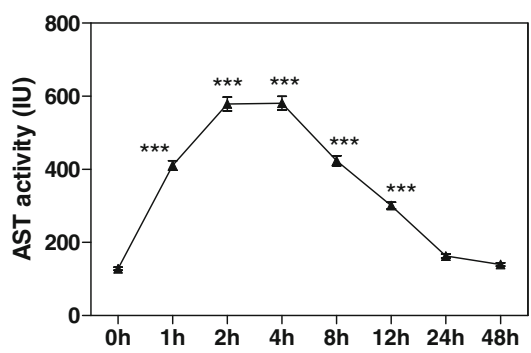

C

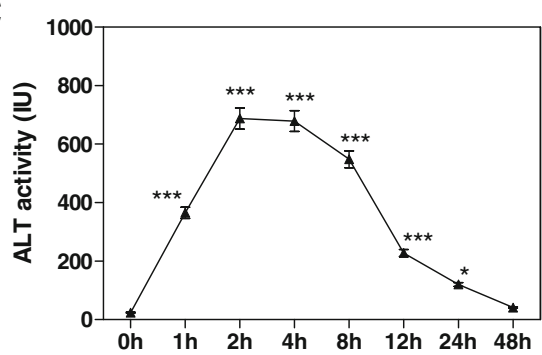

D

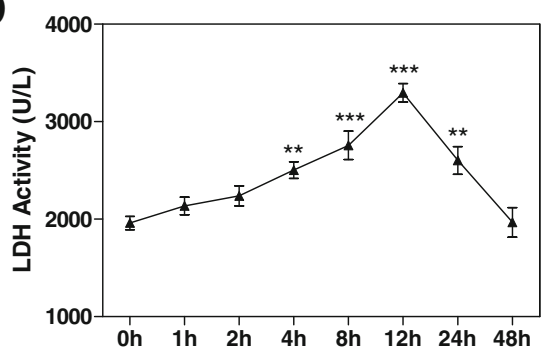

E

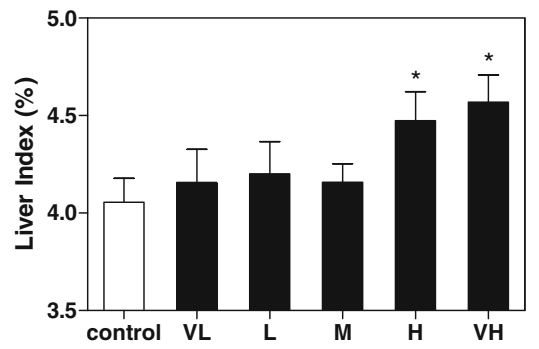

$\mathbf{F}$

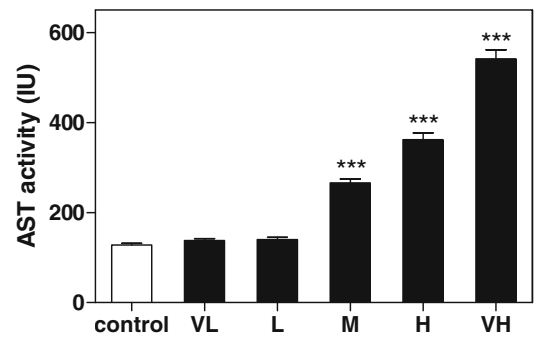

G

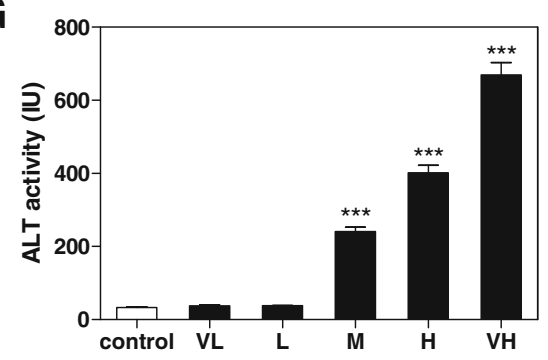

H

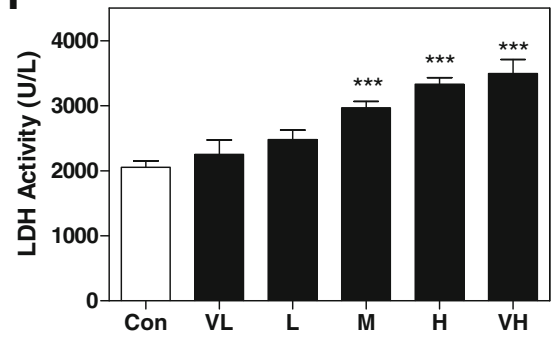

Fig. $\mathbf{2}$ SS-induced liver toxicity. a and e liver index, Serum level of $\mathbf{b}$ and $\mathbf{f} A S T$, $\mathbf{c}$ and $\mathbf{g}$ ALT and $\mathbf{d}$ and $\mathbf{h} L D H$ after different time and dose of SS administration. All the data are presented as mean \pm S.E. $(n=8),{ }^{*} p<0.05,{ }^{* *} p<0.01,{ }^{* *} p<0.001$, compared to time 0 h or vehicle control group, respectively 


\section{Results}

\section{Phytochemical analysis}

HPLC was employed to analyze the typical chromatograms of SS extracts from RB. SSa and SSd Standards were used to identify the components. According to the chromatogram, the major SS were identified from a comparison with the retention times of external standards (SSa: $19.696 \mathrm{~min}, \mathrm{SSd}: 25.473 \mathrm{~min}$ ) and presented peaks at $19.722 \mathrm{~min}$ for SSa, and $25.446 \mathrm{~min}$ for SSd (Fig. 1). SSa and SSd constituted $20.499 \%$ and $26.679 \%$ of SS sample respectively, according to the calculation of peak area. More information is required for the identification of other phytochemicals, including SSb1, SSb2 and SSc.

\section{SS induces acute liver injury in mice}

After SS administration, mice were sacrificed as described in methods. As shown in Fig. 2a, the liver index (liver weight/body weight) was significantly increased beginning at $8 \mathrm{~h}$ after SS administration. Due to the relative short period of SS administration, no appreciable changes were observed during the histopathological examination using hematoxylin and eosin staining (data not shown), with the exception of occasional focal hepatocyte necrosis and inflammatory cell infiltration in the $\mathrm{H}$ group. As shown in Fig. 2b and c, serum AST and ALT levels were significantly elevated as early as $1 \mathrm{~h}$ after the mice were treated with SS, reached peak at approximate $4 \mathrm{~h}$, and gradually recovered from $24 \mathrm{~h}$ to $48 \mathrm{~h}$. Serum LDH activity level, which indicated an impairment of hepatocyte membrane integrity, was also increased at $4 \mathrm{~h}$, and reached peak at $12 \mathrm{~h}$ (Fig. 2d). As shown in Fig. 2e-h, we further demonstrated that SS dose dependently induced elevation of these liver injury makers.

\section{Analysis of SS-induced differentially expressed proteins} We then used an iTRAQ reagent-based quantitative proteome analysis as a global approach to investigate potential proteins and pathways associated with SSinduced liver injury in mice. 1288 proteins were quantified and further used for bioinformatics analysis. In the time-dependent toxicity study, 332 proteins were identified as significantly differentially expressed (fold change $>2, p<0.05$ ), including 149 up-regulated proteins, and 183 down-regulated proteins. According to the GO annotation, the enriched biological pathways were mainly involved in lipid metabolism, carbohydrate metabolism, cofactor metabolic process, protein translation and metabolism, energy homeostasis and cellular response to stress (Fig.3a). In the dose-toxicity study, 654 proteins were identified significantly differentially expressed (fold change $>2, p<0.05$ ). Dose-toxicity study (Fig. 3b) further suggested that SS induced liver toxicity through multiple mechanisms in a time- and dose-related manner.

\section{Time course analysis of SS-regulated biological pathways} In order to identify the causes and consequences of SS-induced liver toxicity, we clustered all differentially expressed proteins observed in the time-toxicity study based on their fold changes over time. 292 proteins out of 302 proteins fit into 8 patterns (Fig. 4a). We then conducted enrichment analysis of GO biological pathways based on the different clustering patterns. According to the enrichment results (Fig. 4b), proteins involved in lipid transportation, lipoprotein metabolic process, and the fatty acid metabolic process were all rapidly up- or down-regulated from $1 \mathrm{~h}$ to $2 \mathrm{~h}$ after SS-administration (Cluster 5 and 8). Proteins involved in the response to stress or toxin, amino acid metabolism and carbohydrate metabolism were significantly regulated at $2 \mathrm{~h}$ or $6 \mathrm{~h}$ after SS-administration and recovered after $24 \mathrm{~h}$ or $48 \mathrm{~h}$ (Cluster 1 and 2). $12 \mathrm{~h}$ after SS administration, energy homeostasis, including ATP synthesis, the tricarboxylic acid cycle and electron transport chain, was significantly
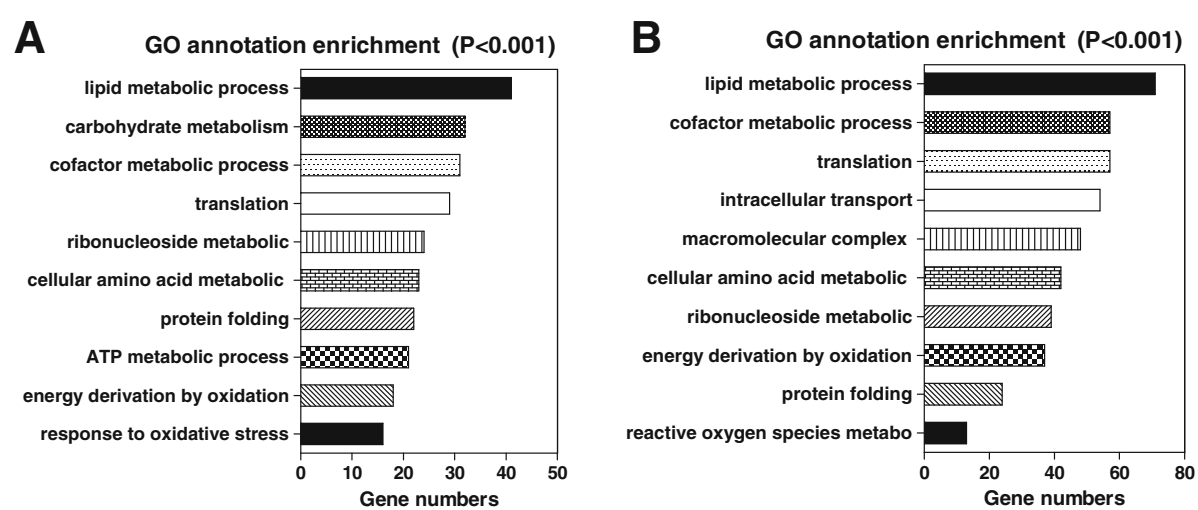

Fig. 3 GO analysis for SS-induced differentiated expressed proteins. GO annotation enriched biological pathways for (a) time-toxicity study and $\mathbf{b}$ dose-toxicity study 

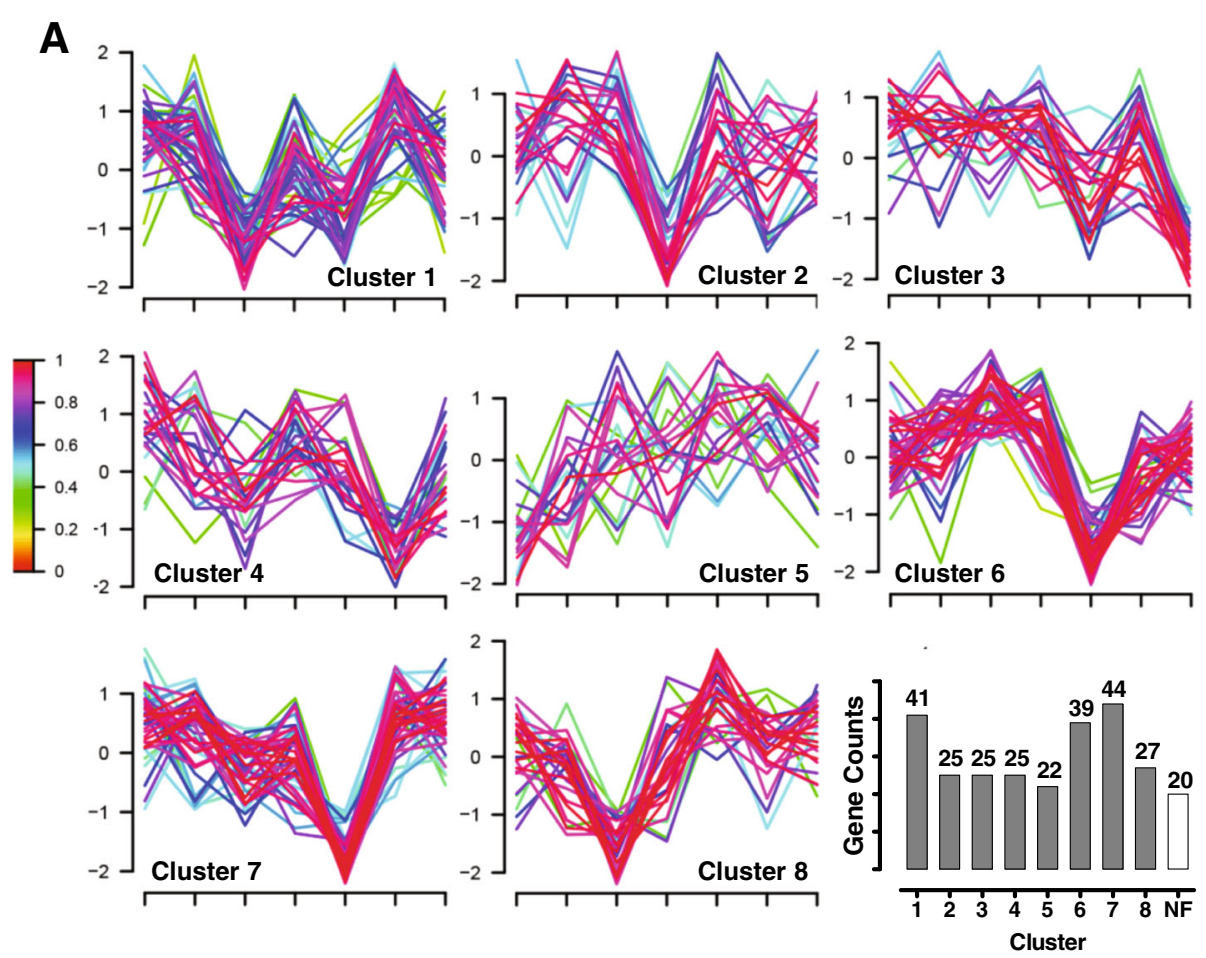

\section{B}
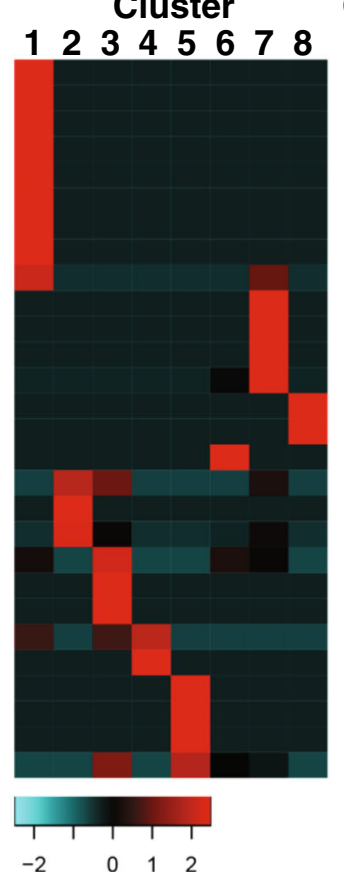

\section{GO annotation}

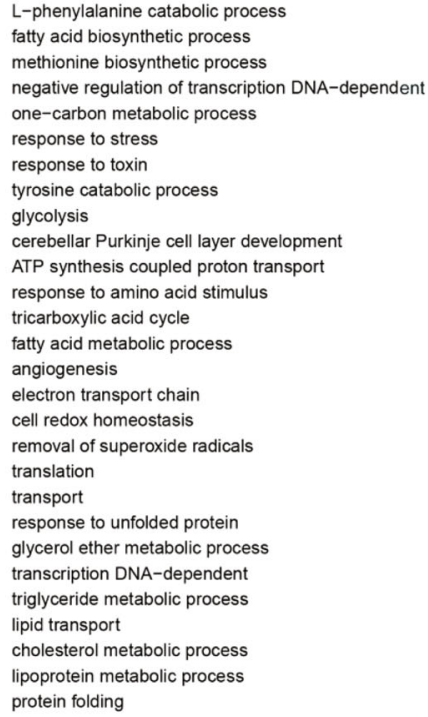

L-phenylalanine catabolic process

fatty acid biosynthetic process

methionine biosynthetic process

negative regulation of transcription DNA-dependent

one-carbon metabolic process

response to stress

response to toxin

tyrosine catabolic process

glycolysis

cerebellar Purkinje cell layer development

ATP synthesis coupled proton transport

response to amino acid stimulus

tricarboxylic acid cycle

fatty acid metabolic process

angiogenesis

electron transport chain

cell redox homeostasis

removal of superoxide radicals

translation

transport

response to unfolded protein

glycerol ether metabolic process

transcription DNA-dependent

triglyceride metabolic process

lipid transport

cholesterol metabolic process

lipoprotein metabolic process

protein folding

Fig. 4 Cluster analysis of SS-regulated proteins in time-toxicity study. a Cluster analysis and profiles. Legend (left) indicates fitness to cluster center. Numbers of protein counts in each cluster were plotted with cluster number (NF indicates non-fit proteins). $\mathbf{b}$ Enrichment of GO biological pathways to cluster profiles

disrupted. In addition, protein translation and protein folding processes were also regulated by SS from $2 \mathrm{~h}$ to $6 \mathrm{~h}$ after administration. Intracellular transport, macromolecular complex metabolic processes were regulated $12 \mathrm{~h}$ after SS exposure and persisted until $24 \mathrm{~h}$ to $48 \mathrm{~h}$.
Based on this evidence, dysregulation of lipid transportation and metabolism occurred prior to, and is a plausible cause of the disruption of other biological pathway, including response to stress, energy homeostasis and protein homeostasis. 


\section{Effects of SS on lipid transport and metabolism}

Because dysregulation of lipid metabolism is the most common features of several liver diseases, we identified 51 proteins enriched in the lipid metabolic process pathway (Fig. 5a). According to the cluster analysis, the expression of genes related to lipoprotein metabolism, cholesterol homeostasis and fatty acid metabolic processes were up-regulated rapidly and then downregulated (Cluster 1), whereas, genes related fatty acid biosynthetic and acyl-CoA metabolism were consistently increased (Cluster 2 and 3) (Fig. 5b-d). As summarized in Table 1, apolipoprotein A (Apo A) - I, II, IV, and V were all significantly upregulated and reached peak earlier than $8 \mathrm{~h}$. ApoA- IV increased 3 folds $2 \mathrm{~h}$ after SS administration, which was the most sensitive and intensive, and persisted more than $48 \mathrm{~h}$. All of these lipoproteins have been shown to participate in lipid transport from other organs to the liver by forming High-density lipoprotein or chylomicron particles, and are also involved in inducing of lipoprotein degradation and lipid metabolism. Additionally, proteins involved in triglyceride (TG) and cholesteryl esters hydrolysis, including Lipase A, were rapidly upregulated at $2 \mathrm{~h}$ after SS administration, which suggested that SS increased TG clearance and fatty acid production in hepatocytes and induced lipotoxicity.

\section{A}

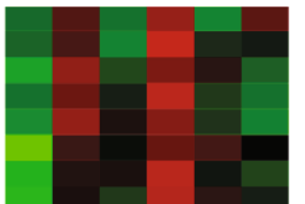

$\mathrm{Gpx} 1$

Acat2

Ces1d

Acads

Pecr

Acadsb

Atp5b

Aldh8a1

Rab7a

Dbi

Cyp2c29

Saa1

Hadh

Stat5a

Crot

Cyp2e1

Hsd17b8

Fabp4

Fdps

Cpt2

Apoa2

Pck1

Lypla1

Lypla1

Acad

Apoc3

Apoa5

Psap

Elovl2

Cyb5a

Akr1c6

Akr1c6

Apoa1

Mif

Atp5a 1

Adh1

Ywhah

Acsm1

Acot2

$\mathrm{Fdx} 1$

Сyp2f2

Scp2

Eci2

Acad11

C3

Sult1a1

Ephx2

Hsd17b4

Gk

Apoa4

Por

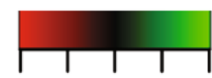

$\begin{array}{lll}-2 & 0 & 2\end{array}$

\section{B}

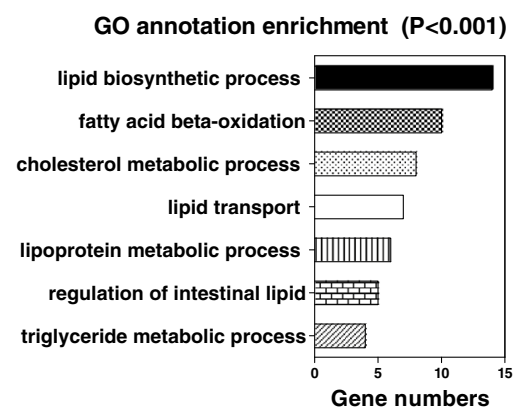

C
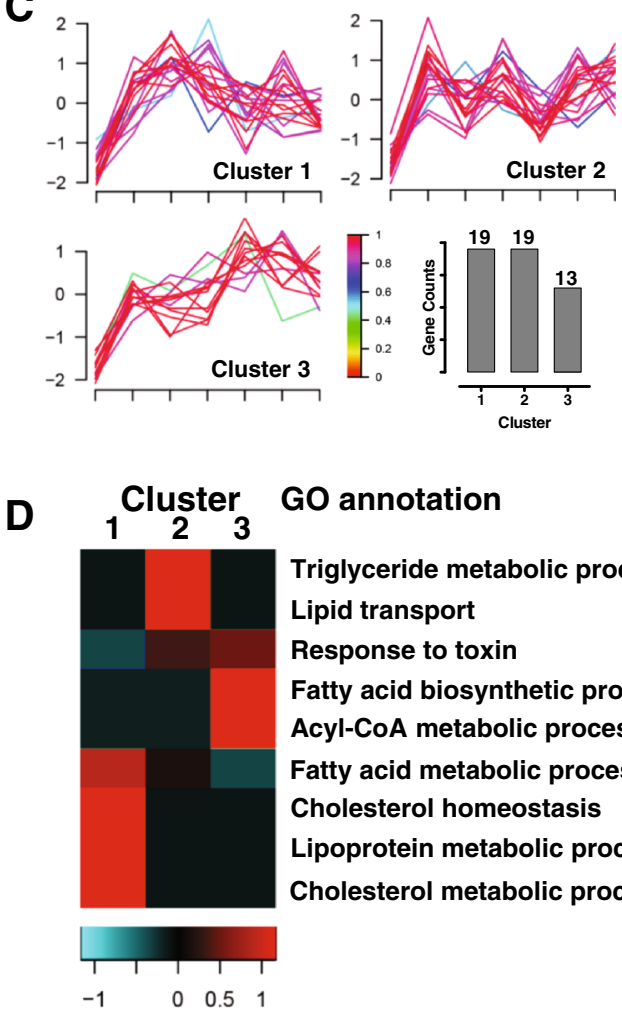

GO annotation

Triglyceride metabolic process

Lipid transport

Response to toxin

Fatty acid biosynthetic process

Acyl-CoA metabolic process

Fatty acid metabolic process

Cholesterol homeostasis

Lipoprotein metabolic process

Cholesterol metabolic process

Fig. 5 Cluster analysis of SS-regulated lipid metabolism related proteins. a The list of SS-regulated proteins involved in lipid metabolism. Legend indicates fold changes (Log). b GO annotation enriched biological pathways based on selected proteins. c Cluster analysis and profiles for selected proteins. $\mathbf{d}$ Enrichment of $\mathrm{GO}$ biological pathways to cluster profiles 
Table 1 Effects of SS on expression of lipid metabolism related proteins

\begin{tabular}{|c|c|c|c|c|}
\hline Protein name & protein ID & fold change & time(h) & protein description \\
\hline \multicolumn{5}{|c|}{ Effect of SS on expression of Lipid transportation related proteins } \\
\hline Apoa4 & P06728 & 3.28 & 8 & Apolipoprotein A-IV \\
\hline Apoa2 & P09813 & 2.22 & 8 & Apolipoprotein A-II \\
\hline Apoa1 & Q00623 & 1.47 & 4 & Apolipoprotein A-I \\
\hline Apoa5 & Q8C7G5 & 1.06 & 2 & Apolipoprotein A-V \\
\hline Saa1 & P05366 & -1.85 & 24 & Serum amyloid A-1 protein \\
\hline \multicolumn{5}{|c|}{ Effect of SS on expression of Lipid metabolism related proteins } \\
\hline Lipa & Q9Z0M5 & 2.12 & 2 & Lipase A \\
\hline Fabp3 & P11404 & 2.86 & 24 & Fatty acid-binding protein \\
\hline Scp2 & P32020 & 1.33 & 24 & Non-specific lipid-transfer protein \\
\hline $\mathrm{Fdx1}$ & P46656 & 1.89 & 24 & Adrenodoxin, mitochondrial \\
\hline Acad11 & Q80XL6 & 1.69 & 24 & Acyl-CoA dehydrogenase family member 11 \\
\hline Acot2 & Q9QYR9 & 1.20 & 48 & Acyl-coenzyme A thioesterase 2 , mitochondrial \\
\hline Fdps & Q920E5 & -1.55 & 24 & Farnesyl pyrophosphate synthase \\
\hline $\operatorname{Sec} 1412$ & Q99J08 & -1.86 & 24 & SEC14-like protein 2 \\
\hline Acsm1 & Q91VA0 & -1.69 & 8 & Acyl-coenzyme A synthetase ACSM1 \\
\hline Dbi & P31786 & -1.29 & 4 & Acyl-CoA-binding protein \\
\hline Acadl & P51174 & -1.33 & 24 & Long-chain specific acyl-CoA dehydrogenase \\
\hline
\end{tabular}

Fold change: peak fold change of certain protein expression

Time(h): time point after SS administration when reach peak fold change

All fold changes are relative to Control group (time point $0 \mathrm{~h}$ )

On the other hand, the up-regulation of several intracellular lipid transporters and components involved in fatty acid oxidation, such as fatty acid-binding protein, non-specific lipid-transfer protein, Acyl-CoA dehydrogenase family member 11 and Acyl-coenzyme A thioesterase 2, Cytochrome P 2E1 (CYP2E1), accompanied with down-regulation of other key enzymes or mediators of lipid metabolism, like Farnesyl pyrophosphate synthase, SEC14-like protein 2, Acyl-coenzyme A synthetase ACSM1, Acyl-CoA-binding protein and Long-chain specific acyl-CoA dehydrogenase, indicated dysregulation of hepatic lipid metabolism. Most of these proteins responded to SS after $12 \mathrm{~h}$, and reached peak at approximately $24 \mathrm{~h}$. As shown in Fig. 6, we observed dosedependent decrease of serum and liver TG and cholesterol level $24 \mathrm{~h}$ after SS administration, indicating that excessive lipid oxidation neutralized increased lipid import in the liver.

\section{Effects of SS on the induction of oxidative stress}

Emerging evidence supported that oxidative stress is one of the most important mechanisms that directly induces damage during drug-induced liver injury. Proteins involved in the removal of superoxide radicals and the response to reactive oxygen species (ROS) were first upregulated at $1 \mathrm{~h}$ to $2 \mathrm{~h}$ and then significantly downregulated at $6 \mathrm{~h}$ after SS administration (Fig. 4a, b).
Sod1, Gpx1, Tgm2, Gsta3, Gstp1 and Dhe3 were all downregulated more than 2 fold $6 \mathrm{~h}$ after SS administration (Table 2). CYP2E1 is particularly susceptible to ROS production, and links dysregulated lipid metabolism to oxidative stress. Protein levels of CYP2E1 were significantly increased $2 \mathrm{~h}$ after SS administration, reached peak at $8 \mathrm{~h}$ and persisted until $24 \mathrm{~h}$ (Fig. 7a, c). The induction of CYP2E1 expression was also dose dependent (Fig. 7b, d). In support of these findings, intrahepatocytes ROS levels were significantly increased $12 \mathrm{~h}$ after SS administration in a dose-dependent manner, and the Glutathione (GSH) level in liver was significantly decreased (Fig. 7e, f). Oxidative stress was further confirmed by dose-dependent elevation of the Malondialdehyde (MDA) level, and increased iNOS expression (Fig. 7g, h).

HepG2 cells were treated with different dose of SS (from $25 \mu \mathrm{g} / \mathrm{mL}$ to $400 \mu \mathrm{g} / \mathrm{mL}$ ) to further confirm the oxidative stress inducing effects of SS. As expected, SS significantly induced cell death of HepG2 $24 \mathrm{~h}$ after administration, with an IC50 less then $200 \mu \mathrm{g} / \mathrm{mL}$ (Fig. 8a). Intracellular ROS levels were dose-dependently increased $12 \mathrm{~h}$ after treatment, accompanied with depleted GSH level and increased iNOS activity (Fig. 8b-d). All these changes suggested that SS-induced excessive but dysregulated lipid metabolisms leaded to increased ROS production and following oxidative stress. 
A
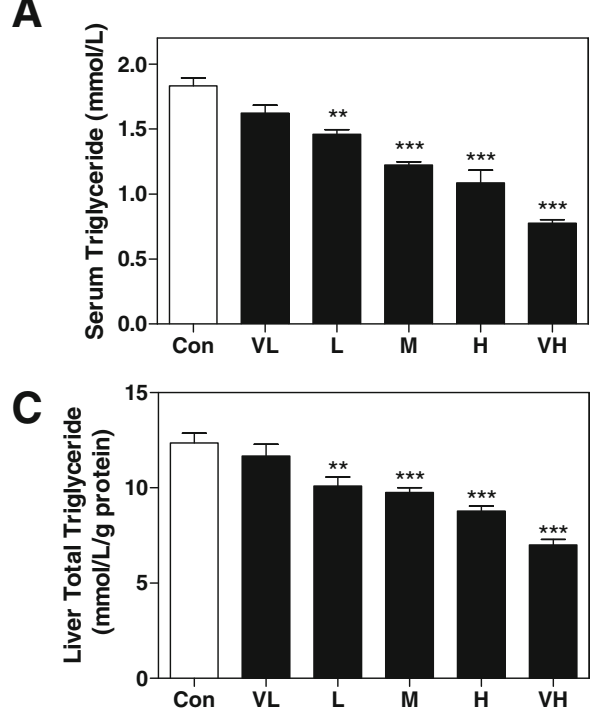

B

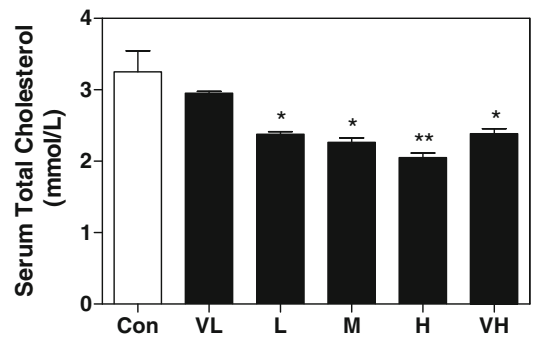

D 홍

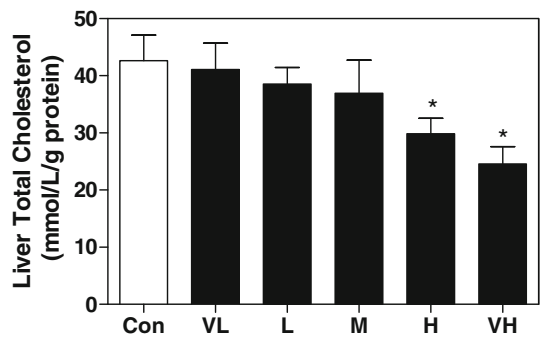

Fig. 6 Effect of SS on lipid contents in serum and liver. a TG and $\mathbf{b}$ total cholesterol in serum, and c TG, d total cholesterol level in liver. All results are presented as mean \pm S.E. $(n=8),{ }^{*} p<0.05,{ }^{* *} p<0.01,{ }^{* * *} p<0.001$, compared to vehicle control group

Effects of SS on protein translation and degradation

Enriched GO biological pathways analysis also suggested altered protein translation and metabolism in the SStreated mouse liver. As summarized in Table 3, proteins required for mRNA maturation and small nuclear ribonucleoprotein biogenesis, were either up-regulated or down-regulated within a relatively short period after SS exposure. In addition, several ribosome components were significantly downregulated beginning at $4 \mathrm{~h}$ after $\mathrm{SS}$ administration, reached peak at $8 \mathrm{~h}$ that persisted for over $24 \mathrm{~h}$. The disruption of the ribosome will eventually leads to a global inhibition of protein translation and contributes to the loss of cellular functions. Additionally, correct protein folding is essential for protein maturation and biological function. However, our proteomic analysis indicated that several proteins involved in

Table 2 Effect of SS on expression of proteins related to response to oxidative stress

\begin{tabular}{lllll}
\hline $\begin{array}{l}\text { Protein } \\
\text { name }\end{array}$ & protein ID & High & low & protein description \\
\hline Ggt1 & Q60928 & 1.30 & 0.74 & Gamma-glutamyltranspeptidase 1 \\
Sod1 & P08228 & 1.25 & 0.58 & Superoxide dismutase [Cu-Zn] \\
Gpx1 & P11352 & 1.57 & 0.17 & Glutathione peroxidase 1 \\
Cycs & P62897 & 1.38 & 1.00 & Cytochrome c, somatic \\
Glo1 & Q9CPU0 & 1.33 & 0.60 & Lactoylglutathione lyase \\
Rgn & Q64374 & -1.13 & -0.65 & Regucalcin \\
Bag5 & Q8Cl32 & -1.47 & -0.35 & BAG family molecular chaperone \\
& & & & regulator 5 \\
\hline
\end{tabular}

High/Low: indicate fold changes of certain proteins after high dose or low dose of SS administration

All fold changes are relative to Control group assisting protein folding in the endoplasmic reticulum were down-regulated. Furthermore, the levels of several proteasome components were increased, indicating that the protein degradation mechanism may have been upregulated. All these confusion results demonstrated that the protein homeostasis and regular protein translationfolding-degradation processes were disrupted by SS and may have contributed to the failure of the hepatocyte repair mechanism and subsequent apoptosis.

\section{Effects of SS on cellular organization and intracellular transport-related proteins}

The cellular organization and intracellular transport systems are not only critical for macromolecular uptake and metabolism, but are also essential for other functions such as bile secretion and uptake in hepatocytes. Our proteomic results demonstrated that several important proteins related to cytoskeleton stabilization were dose dependently decreased $8 \mathrm{~h}$ after SS administration. Consistent with these findings, significant morphological changes of HepG2 cells, from a polygon to a shrinking circle, were observed $12 \mathrm{~h}$ after SS treatment, prior to cell death (Fig. 8e). In addition, several intracellular transportrelated proteins were also significantly down-regulated as well (Table 4). The disruption of cytoskeleton stability and disturbance of intracellular transport directly lead to hepatocyte dysfunction and following liver injury.

\section{Discussion}

As demonstrated in our previous studies, SS are primary ingredients responsible for RB-induced hepatic adverse effects $[15,16]$. In the current study, SS induced time- 


\section{A}
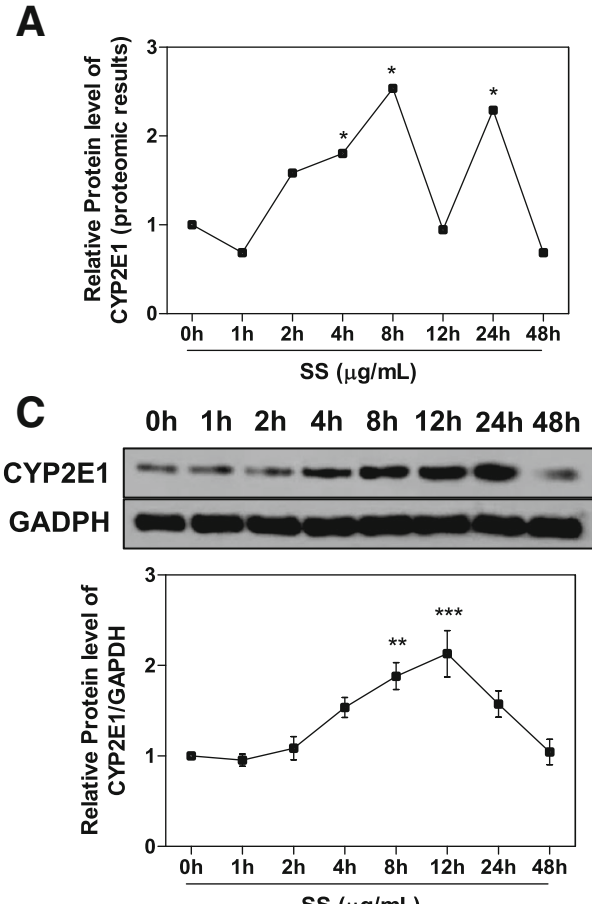

E

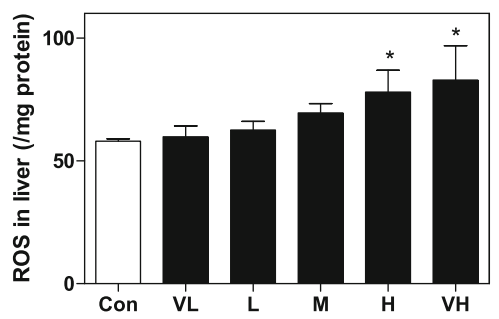

G

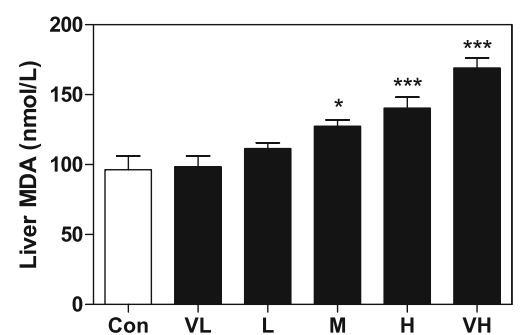

B

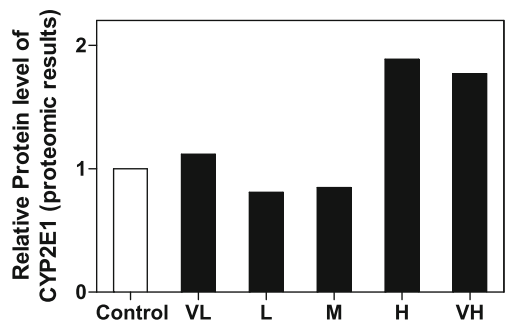

$\begin{array}{lllllll}D & \text { Control VL } & \text { L } & \text { M } & \text { H } & \text { VH }\end{array}$

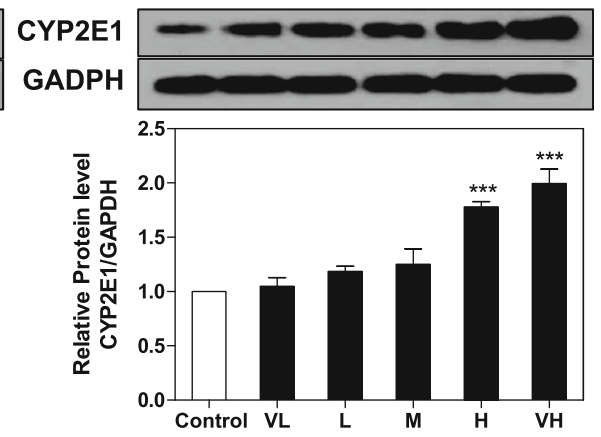

$\mathbf{F}$

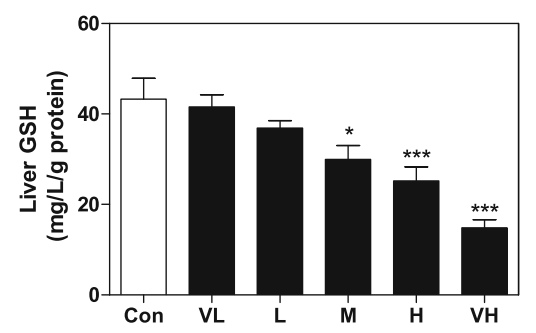

H

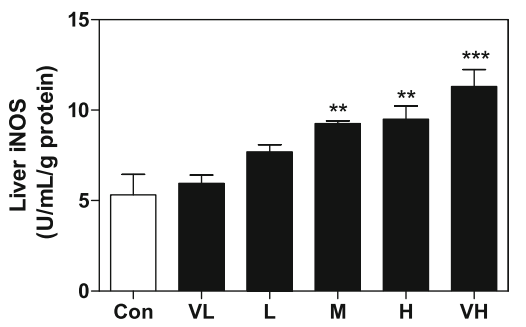

Fig. 7 SS-induced oxidative stress in mice liver. Proteomic results for CYP2E1 expression in a time-toxicity study and $\mathbf{b}$ dose-toxicity study. ${ }^{*} p$ value $<0.05$. Proteins levels of CYP2E1 in c time-toxicity study and $\mathbf{d}$ dose-toxicity study were determined by western blot. Representative images of immunoblots are shown and analyzed using GAPDH as loading control. Effects of different dose of SS administration on e ROS, $\mathbf{f}$ GSH, $\mathbf{g}$ MDA and $\mathbf{h}$ iNOS level in liver. All results are presented as mean \pm S.E. $(n=8),{ }^{*} p<0.05,{ }^{* *} p<0.01,{ }^{* * *} p<0.001$, compared to vehicle control group

and dose-dependent acute liver injury in mice. Dysfunction of lipid metabolism and dysregulation of lipid homeostasis were critical causes, as well as consequences of liver injury. In addition to the up-regulation of Apolipoproteins, the transport of TG and cholesterol from other organs to liver for oxidation or secretion was significantly increased in a short time period after SS administration. The increased levels of critical enzymes involved in TG and cholesterol hydrolysis such as Lipase A, further accelerated lipid clearance from the circulation and liver. Under normal conditions, the cleavage of TG and cholesterol significantly reduced risk of atherosclerosis, alleviated insulin resistance and maintained liver and body lipid homeostasis, suggesting potential pharmacological effects of SS [24, 25]. However, the regulation of fatty acid metabolism in the liver was paradoxically dysregulated after SS administration. Proteins involved in fatty acid uptake and $\beta$-oxidation, such as Acot 2 and Acad11, were up-regulated, whereas other proteins, such as Acad1, were significantly down regulated [26]. When 

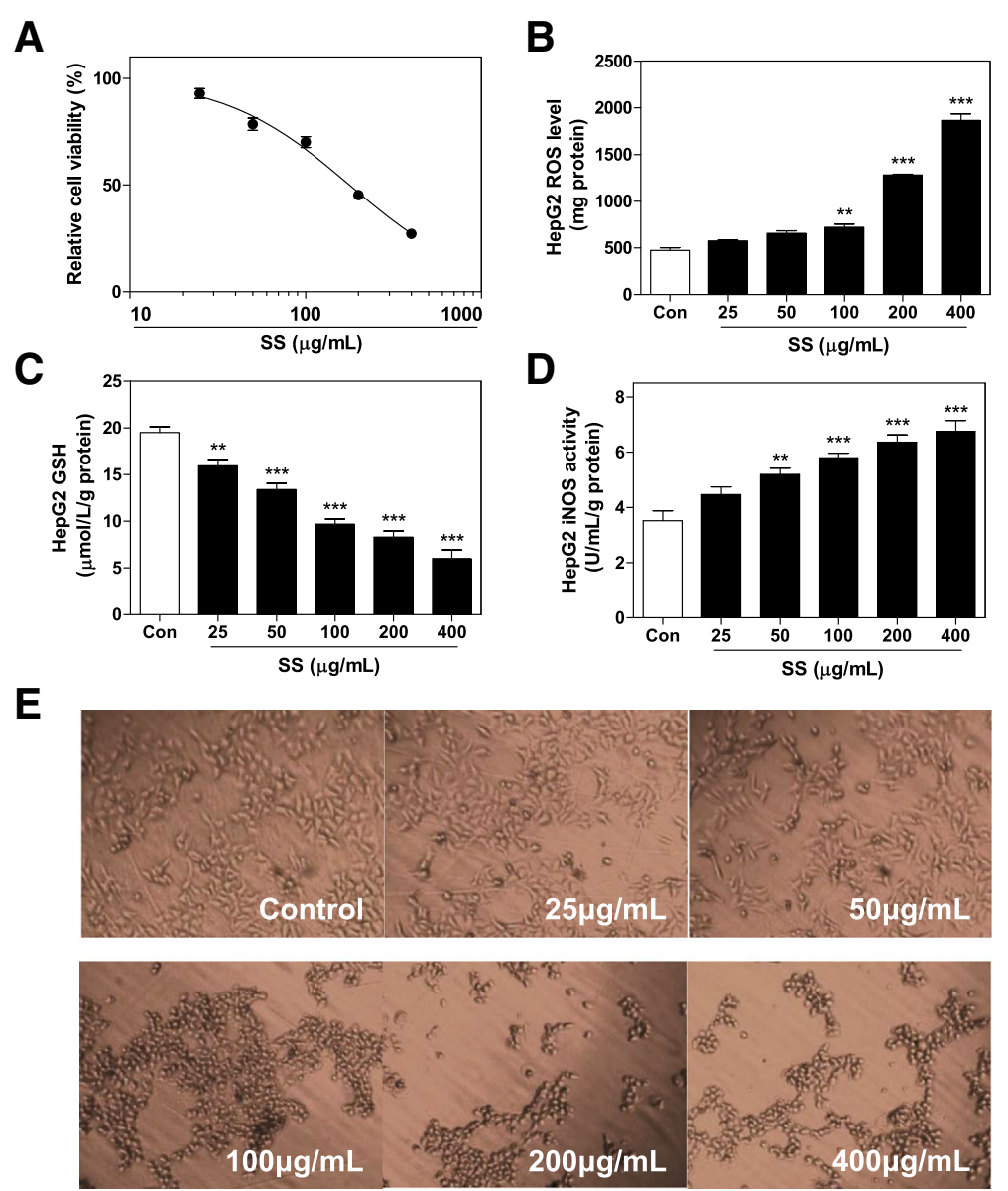

Fig. 8 Effects of SS on HepG2 cells. a Effects of SS on cell viability of HepG2 cells after $24 \mathrm{~h}$ treatment. Effects of $12 \mathrm{~h}$ treatment of SS on $\mathbf{b}$ ROS, c GSH and $\mathbf{d}$ iNOS level in HepG2 cells. e Effects of SS on morphology changes of HepG2 cells after $12 \mathrm{~h}$ treatment. All results are presented as mean \pm S.E. $(n=3),{ }^{* *} p<0.01,{ }^{* *} p<0.001$, compared to vehicle control group

the SS-induced excess lipids are imported into the liver, this disordered expression will subsequently disturb fatty acid metabolism in hepatocytes and induce lipotoxicity.

Emerging evidence supported that dysregulation of lipid metabolism, intracellular accumulation of fatty acids and impairments of fatty acid $\beta$-oxidation presumably stimulated ROS production by promoting electron overflow in the mitochondrial respiration chain [27, 28]. Excessive ROS levels overwhelmed the anti-oxidation mechanism, and will then damage hepatocytes [29]. Furthermore, the significant induction of CYP2E1 expression by SS was an important source of ROS production by enhanced omega fatty acid oxidation [30]. As a consequence of unresolved oxidative stress, significant lipid peroxidation, which has been characterized as an important cause and marker of drug-induced liver injury due to its critical role in membrane integrity impairment, was also observed by monitoring liver MDA level in our study. Oxidative stress significantly induced iNOS expression, which further contributed to liver dysfunction and damage by induction of chronic inflammation and endothelial disruption. Mitochondrial membrane potency was also significantly disrupted as a consequence of excessive oxidative stress (Data not shown). On the other hand, the levels of some proteins that protect cells against mitochondrial damage or apoptosis, including Bag5 and Rgn, were remarkably down-regulated [31, 32]. These results provided important evidence suggesting that ROS production following oxidative stress and related damage serves as an important mechanism in SS-induced liver injury.

The accumulation of fatty acids, particularly longchain and saturated fatty acids, has been suggested to be involved in inducing endoplasmic reticulum stress and disrupting lipid metabolism in liver diseases [33]. Fatty acids-induced oxidative stress, disturbances of calcium homeostasis and altered membrane lipid saturation were considered to be three main mechanisms [34, 35]. Apoptosis driven by CHOP and JNK activation will be triggered once cells failed to recover from endoplasmic reticulum stress [36]. Furthermore, our proteomics 
Table 3 Effects of SS on expression of protein metabolism related proteins

\begin{tabular}{|c|c|c|c|c|}
\hline Protein name & protein ID & fold change & time(h) & protein description \\
\hline \multicolumn{5}{|c|}{ Effect of SS on expression of translation related proteins } \\
\hline Sfrs5 & O35326 & 1.24 & 4 & Splicing factor, arginine/serine-rich 5 \\
\hline Sfrs7 & Q8BL97 & 1.49 & 2 & Splicing factor, arginine/serine-rich 7 \\
\hline Ptbp1 & P17225 & 1.59 & 2 & Polypyrimidine tract-binding protein 1 \\
\hline Ruxe & P62305 & -1.38 & 24 & Small nuclear ribonucleoprotein $\mathrm{E}$ \\
\hline Smd2 & P62317 & -1.17 & 2 & Small nuclear ribonucleoprotein Sm D2 \\
\hline Npm1 & Q61937 & -1.09 & 8 & Nucleophosmin \\
\hline Rps16 & P14131 & -2.29 & 8 & $40 S$ ribosomal protein $\mathrm{S} 16$ \\
\hline Rpsa & P14206 & -1.41 & 8 & $40 S$ ribosomal protein SA \\
\hline Rps14 & P62264 & -1.08 & 8 & $40 \mathrm{~S}$ ribosomal protein $\mathrm{S} 14$ \\
\hline Rps24 & P62849 & -1.09 & 8 & $40 \mathrm{~S}$ ribosomal protein $\mathrm{S} 24$ \\
\hline $\operatorname{Rps} 28$ & P62858 & -1.32 & 24 & $40 \mathrm{~S}$ ribosomal protein $\mathrm{S} 28$ \\
\hline Rps19 & Q9CZX8 & -1.40 & 24 & $40 S$ ribosomal protein S19 \\
\hline \multicolumn{5}{|c|}{ Effect of SS on expression of post-translation modification related proteins } \\
\hline Pmpcb & Q9CXT8 & 3.51 & 8 & Mitochondrial-processing peptidase subunit beta \\
\hline Hspa2 & P17156 & 1.50 & 8 & Heat shock-related $70 \mathrm{kDa}$ protein 2 \\
\hline Hsp90ab1 & P11499 & -1.28 & 8 & Heat shock protein HSP 90-beta \\
\hline P4hb & P09103 & -1.33 & 4 & Protein disulfide-isomerase \\
\hline Pdia3 & P27773 & -1.27 & 24 & Protein disulfide-isomerase A3 \\
\hline Pdia6 & Q922R8 & -2.38 & 8 & Protein disulfide-isomerase A6 \\
\hline Canx & P35564 & -1.38 & 8 & Calnexin \\
\hline Erp44 & Q9D1Q6 & -1.91 & 8 & Endoplasmic reticulum resident protein 44 \\
\hline Psmd14 & O35593 & 1.37 & 8 & 265 proteasome non-ATPase regulatory subunit 14 \\
\hline Pmsa5 & Q9Z2U1 & 1.53 & 4 & Proteasome subunit alpha type- 5 \\
\hline Psmb9 & P28076 & 1.23 & 24 & Proteasome subunit beta type- 9 \\
\hline
\end{tabular}

Fold change: peak fold change of certain protein expression

Time(h): time point after SS administration when reach peak fold change

All fold changes are relative to Control group (time point $0 \mathrm{~h}$ )

results suggested that the mechanism by which SS disrupted protein expression was more complicated and severe. Global protein dysregulation will then induce cytoskeletal disorganization, dysfunctional intracellular transport and also impaired membrane organization [37]. Dysregulation of protein metabolism not only disrupted normal liver function but also interfered with the hepatoprotective and recover mechanism of liver against stress, subsequently leaded to SS-induced hepatocytes apoptosis or necrosis, consistent with clinical and pathological findings [9].

Interestingly, according to our dose-toxicity study, significant acute liver injury only occurred when the animals were administered a dose greater than $12.957 \mathrm{mg} /$ $\mathrm{kg}$, which is approximately 8 folds higher than the safety daily dose used clinically. This finding highlighted the risks of adverse effects following an acute overdose of RB-containing prescriptions, and provided experimental evidence of a quantified dose-toxicity relationship, which will promote the safe clinical use of RB-containing products. Further studies are still required to elucidate the plausible mechanism underlying long-term consumption of RB-induced toxicity. Critical biological pathways identified in this acute liver injury model are also likely involved in the chronic hepatotoxicity of SS. Furthermore, it was noteworthy that in L group, although no significant liver injury was observed, several biological pathways, including lipid transportation and metabolism, were still significantly regulated by SS administration. In support of this finding, several studies demonstrated that relatively low dose of SS alleviated chronic liver diseases, including fatty liver, fibrosis, cancer or chemical-induced liver injury [38]. These findings suggested that SSinduced bioactive effects, either pharmacological or toxicological, were dose sensitive. In contrast to maintaining hepatic metabolism homeostasis and hepatoprotective effects of SS at a pharmacological dose, SS overdose induced excess disturbances of several vital biological 
Table 4 Effect of SS on expression of cytoskeleton organization and intra-cellular transportation related proteins

\begin{tabular}{lllll}
\hline $\begin{array}{l}\text { Protein } \\
\text { name }\end{array}$ & protein ID & High & low & protein description \\
\hline Gsna & P13020 & -2.44 & -0.44 & Gelsolin \\
Flna & Q8BTM8 & -1.35 & -0.21 & Filamin-A \\
Lpin1 & Q91ZP3 & -1.46 & -1.40 & Phosphatidate phosphatase LPIN1 \\
Racgap & Q9WVM1 & -2.35 & -1.71 & Rac GTPase-activating protein 1 \\
Chp1 & P61022 & -2.86 & -1.42 & Calcineurin B homologous protein 1 \\
Rab10 & P61027 & -4.01 & -1.06 & Ras-related protein Rab-10 \\
Rab-7a & P51150 & -1.77 & -0.54 & Ras-related protein Rab-7a \\
Rab-5C & P35278 & -2.59 & -0.70 & Ras-related protein Rab-5C \\
Nras & P08556 & -2.52 & -0.61 & GTPase Nras \\
Vps4b & P46467 & -2.25 & -0.19 & Vacuolar protein sorting-associating \\
& & & & protein 4B \\
Cit & P49025 & -1.55 & -0.73 & Citron Rho-interacting kinase
\end{tabular}

High/Low: indicate fold changes of certain proteins after high dose or low dose of SS administration

All fold changes are relative to Control group

functions and resulted in liver injury. In addition to critical control of dose during clinical practice, compatibility art of TCM provides another common strategy to attenuated potential toxicity of RB. Hepatic protective herbs, including licorice, were widely used as herb pairs with $R B$ in famous Chinese herbal formulas, Chai-Hu-Shu-Gan-San, Long-Dan-Xie-GanTang and Xiao-Chai-Hu-Tang, for the treatment of hepatitis, cold and fever [39-42].

\section{Conclusion}

In conclusion, SS induced severe dysregulation of lipid metabolism and protein expression, which further presumably induced excess ROS generation and hepatocyte apoptosis. Several plausible mechanisms, including lipid metabolism pathways, oxidative stress, mitochondrial damage and dysregulation of global protein metabolism are subjects for further studies. In addition to establishing dose- time course-liver toxicity relationship in a mouse model, the current study provides experimental evidence for the safe clinical use of RB-containing remedies, and new insights into understanding the mechanisms by which SS and RB induce hepatotoxicity.

\section{Abbreviations}

ApoA: Apoliprotein A; CYP2E1: Cytochrome P 2E1; GSH: Glutathione; MDA: Malondialdehyde; RB: Radix Bupleuri; ROS: Reactive oxygen species; SS: Saikosaponins; TCM: Traditional Chinese Medicine; TG: Triglyceride

\section{Funding}

This work was supported by grants from the National Natural Science Foundation of China (Grant No. 81073148, 30,672,649, 81,374,059); the National Major Fundamental Research Program of China (Grant No. 2009CB522802); the Project supported by the Shandong Committee of Science and Technology, China (Grant No. 2008GG2NS02021); the Key Project of Shandong Natural Science Foundation of China (Grant No. ZR2011HZ005). R. Sun is supported by "Traditional Chinese medicine pharmacology and toxicology expert", the post of Taishan scholar.

\section{Availability of data and materials}

The datasets used and/or analysed during the current study are available from the corresponding author on reasonable request.

\section{Authors' contributions}

$\mathrm{RL}, \mathrm{RS}$ conceived the original ideas, designed the study, analyzed the data and wrote the manuscript; $X L, H Y$, JL and $Y L$ carried out the experiments and data analysis. LL helped data analysis. All authors read and approved the final manuscript.

\section{Competing interests}

The authors declare that they have no competing interests.

\section{Consent for publication}

Not applicable.

\section{Ethics approval}

All animal experiments were approved by the Animal experimental ethics committee of Shandong Academy of Traditional Chinese Medicine, and were carried out in accordance with institutional guidelines and ethics.

\section{Plant material statement}

RB, dry roots of Bupleurum chinense DC. (Apiaceae) and Bupleurum scorzonerifolium Willd, is commercially available in China, in accordance with Chinese pharmacopoeia and GMP standards. No raw plant material was used in current study. Deposition of voucher specimen to publicly available herbarium is not applicable.

\section{Publisher's Note}

Springer Nature remains neutral with regard to jurisdictional claims in published maps and institutional affiliations.

\section{Author details}

${ }^{1}$ Department of Medical Pathomorphology, Shandong Academy of Traditional Chinese Medicine, Jinan 250014, Shandong, China. ${ }^{2}$ Jiangsu Key Laboratory of Drug Screening, China Pharmaceutical University, Nanjing, Jiangsu 210009, China. ${ }^{3}$ Department of Microbiology and Immunology, Virginia Commonwealth University, Richmond, VA 23220, USA. ${ }^{4}$ The Post of Taishan Scholar in Traditional Chinese Medicine Pharmacology and Toxicology Expert, Jinan, Shandong 250014, China. ${ }^{5}$ Third Degree Laboratory of Chinese Medicine Pharmacology, State Administration of Traditional Chinese Medicine, Shandong Academy of Traditional Chinese Medicine, Jinan 250014, Shandong, China.

Received: 22 February 2017 Accepted: 7 April 2017

Published online: 19 April 2017

\section{References}

1. Ashour ML, Wink M. Genus Bupleurum: a review of its phytochemistry, pharmacology and modes of action. J Pharm Pharmacol. 2011;63(3):305-21.

2. $L i X Q, G a o Q T$, Chen XH, Bi KS. High performance liquid chromatographic assay of saikosaponins from radix Bupleuri in China. Biol Pharm Bull. 2005; 28(9):1736-42.

3. Lee $\mathrm{CH}$, Wang JD, Chen PC. Risk of liver injury associated with Chinese herbal products containing radix bupleuri in 639,779 patients with hepatitis B virus infection. PLoS One. 2011;6(1):e16064.

4. Hirayama C, Okumura M, Tanikawa K, Yano M, Mizuta M, Ogawa N. A multicenter randomized controlled clinical trial of Shosaiko-to in chronic active hepatitis. Gastroenterol Jpn. 1989;24(6):715-9.

5. Tajiri H, Kozaiwa K, Ozaki Y, Miki K, Shimuzu K, Okada S. Effect of sho-saikoto(xiao-chai-hu-tang) on $\mathrm{HBeAg}$ clearance in children with chronic hepatitis $B$ virus infection and with sustained liver disease. Am J Chin Med. 1991; 19(2):121-9.

6. Oka H, Yamamoto S, Kuroki T, Harihara S, Marumo T, Kim SR, Monna T, Kobayashi K, Tango T. Prospective study of chemoprevention of hepatocellular carcinoma with Sho-saiko-to (TJ-9). Cancer. 1995;76(5):743-9. 
7. Wong WW, Law MY, Hui AY, Lo AO, Li CY, Soo MT, Leung HY, Chan HL. A hospital clinic-based survey on traditional Chinese medicine usage among chronic hepatitis B patients. Complement Ther Med. 2005;13(3):175-82.

8. Aiba T, Takahashi T, Suzuki K, Okoshi S, Nomoto M, Uno K, Aoyagi Y. Liver injury induced by a Japanese herbal medicine, sairei-to (TJ-114, Bupleurum and Hoelen Combination, Chai-Ling-Tang) R1. J Gastroenterol Hepatol. 2007; 22(5):762-3

9. Itoh S, Marutani K, Nishijima T, Matsuo S, Itabashi M. Liver injuries induced by herbal medicine, syo-saiko-to (xiao-chai-hu-tang). Dig Dis Sci. 1995;40(8): $1845-8$.

10. Hsu LM, Huang YS, Tsay SH, Chang FY, Lee SD. Acute hepatitis induced by Chinese hepatoprotective herb, xiao-chai-hu-tang. J Chin Med Assoc. 2006; 69(2):86-8.

11. Mantani N, Kogure T, Sakai S, Goto H, Shibahara N, Kita T, Shimada Y, Terasawa K. Incidence and clinical features of liver injury related to Kampo (Japanese herbal) medicine in 2,496 cases between 1979 and 1999: problems of the lymphocyte transformation test as a diagnostic method. Phytomedicine. 2002;9(4):280-7.

12. Huang $H Q$, Zhang X, Xu ZX, Su J, Yan SK, Zhang WD. Fast determination of saikosaponins in Bupleurum by rapid resolution liquid chromatography with evaporative light scattering detection. J Pharm Biomed Anal. 2009;49(4): 1048-55.

13. Yuan B, Yang R, Ma Y, Zhou S, Zhang X, Liu Y. A systematic review of the active saikosaponins and extracts isolated from Radix Bupleuri and their applications. Pharm Biol. 2017;55(1):620-35.

14. Huang W, Sun R. Study on hepatotoxicity on rats caused by crude extracts of total saikosaponins and correlation with oxidative damage mechanism. Zhongguo Zhong Yao Za Zhi. 2010;35(13):1745-9.

15. Lv L, Huang W, Yu X, Ren H, Sun R. Comparative research of different Bupleurum chinense composition to influence of hepatotoxicity of rats and oxidative damage mechanism. Zhongguo Zhong Yao Za Zhi. 2009;34(18): 2364-8

16. Huang W, Sun R, Zhang Z. "Dose-time-toxicity" relationship study on hepatotoxicity caused by multiple dose of total Bupleurum saponin crude extracts to rats. Zhongguo Zhong Yao Za Zhi. 2010;35(24):3344-7.

17. Sun R, Huang W. "Dose-toxicity" relationship study on rat's chronic hepatoxicity of refined products of saikosaponin by alcohol elution. Zhongguo Zhong Yao Za Zhi. 2010:35(17):2338-41.

18. Wang Y, Yang B, Wu C, Zheng Z, Yuan Y, Hu Z, Ma H, Li S, Liao M, Wang Q. Plasma and liver proteomic analysis of 3Z-3-[(1 H-pyrrol-2-yl)-methylidene]-1(1-piperidinylmethyl)-1,3-2H-indol-2 -one-induced hepatotoxicity in Wistar rats. Proteomics. 2010;10(16):2927-41.

19. Xu C, Zhang X, Yu C, Lu G, Chen S, Xu L, Ding W, Shi Q, Li Y. Proteomic analysis of hepatic ischemia/reperfusion injury and ischemic preconditioning in mice revealed the protective role of ATP5beta. Proteomics. 2009;9(2):409-19.

20. Caubet C, Lacroix C, Decramer S, Drube J, Ehrich JH, Mischak H, Bascands JL, Schanstra JP. Advances in urinary proteome analysis and biomarker discovery in pediatric renal disease. Pediatr Nephrol. 2010;25(1):27-35.

21. Thongboonkerd V. Practical points in urinary proteomics. J Proteome Res. 2007;6(10):3881-90.

22. Rigbolt KT, Vanselow JT, Blagoev B. GProX, a user-friendly platform for bioinformatics analysis and visualization of quantitative proteomics data. Mol Cell Proteomics. 2011:10(8) doi:10.1074/mcp.0110. 007450.

23. Liu R, Li X, Qiang X, Luo L, Hylemon PB, Jiang Z, Zhang L, Zhou H. Taurocholate Induces Cyclooxygenase-2 Expression via the Sphingosine 1phosphate Receptor 2 in a Human Cholangiocarcinoma Cell Line. J Biol Chem. 2015;290(52):30988-1002.

24. Lee $\mathrm{CH}$, Olson P, Evans RM. Minireview: lipid metabolism, metabolic diseases, and peroxisome proliferator-activated receptors. Endocrinology. 2003;144(6): 2201-7.

25. Kontush A, Chapman MJ. Functionally defective high-density lipoprotein: a new therapeutic target at the crossroads of dyslipidemia, inflammation, and atherosclerosis. Pharmacol Rev. 2006;58(3):342-74.

26. Lefebvre P, Chinetti G, Fruchart JC, Staels B. Sorting out the roles of PPAR alpha in energy metabolism and vascular homeostasis. J Clin Invest. 2006; 116(3):571-80

27. Nakamura S, Takamura T, Matsuzawa-Nagata N, Takayama H, Misu H, Noda $\mathrm{H}$, Nabemoto S, Kurita S, Ota T, Ando H, et al. Palmitate induces insulin resistance in H4IIEC3 hepatocytes through reactive oxygen species produced by mitochondria. J Biol Chem. 2009;284(22):14809-18.
28. Vial G, Dubouchaud H, Couturier K, Cottet-Rousselle C, Taleux N, Athias A, Galinier A, Casteilla L, Leverve XM. Effects of a high-fat diet on energy metabolism and ROS production in rat liver. J Hepatol. 2011;54(2):348-56.

29. Begriche K, Massart J, Robin MA, Borgne-Sanchez A, Fromenty B. Druginduced toxicity on mitochondria and lipid metabolism: mechanistic diversity and deleterious consequences for the liver. J Hepatol. 2011;54(4):773-94.

30. Chtioui H, Semela D, Ledermann M, Zimmermann A, Dufour JF. Expression and activity of the cytochrome P450 2E1 in patients with nonalcoholic steatosis and steatohepatitis. Liver Int. 2007;27(6):764-71.

31. Wang X, Guo J, Fei E, Mu Y, He S, Che X, Tan J, Xia K, Zhang Z, Wang G, et al. BAG5 protects against mitochondrial oxidative damage through regulating PINK1 degradation. PLoS One. 2014;9(1):e86276.

32. Yamaguchi M. The anti-apoptotic effect of regucalcin is mediated through multisignaling pathways. Apoptosis. 2013;18(10):1145-53.

33. Malhi H, Kaufman RJ. Endoplasmic reticulum stress in liver disease. J Hepatol. 2011;54(4):795-809.

34. Egnatchik RA, Leamy AK, Jacobson DA, Shiota M, Young JD. ER calcium release promotes mitochondrial dysfunction and hepatic cell lipotoxicity in response to palmitate overload. Mol Metab. 2014;3(5):544-53.

35. Tyra HM, Spitz DR, Rutkowski DT. Inhibition of fatty acid oxidation enhances oxidative protein folding and protects hepatocytes from endoplasmic reticulum stress. Mol Biol Cell. 2012;23(5):811-9.

36. Wei Y, Wang D, Gentile CL, Pagliassotti MJ. Reduced endoplasmic reticulum luminal calcium links saturated fatty acid-mediated endoplasmic reticulum stress and cell death in liver cells. Mol Cell Biochem. 2009;331(1-2):31-40.

37. Gissen P, Arias IM. Structural and functional hepatocyte polarity and liver disease. J Hepatol. 2015;

38. Hong M, Li S, Tan HY, Wang N, Tsao SW, Feng Y. Current Status of Herbal Medicines in Chronic Liver Disease Therapy: The Biological Effects, Molecular Targets and Future Prospects. Int J Mol Sci. 2015;16(12):28705-45.

39. Wang S, Hu Y, Tan W, Wu X, Chen R, Cao J, Chen M, Wang Y. Compatibility art of traditional Chinese medicine: from the perspective of herb pairs. J Ethnopharmacol. 2012;143(2):412-23.

40. Liu CY, Chu JY, Chiang JH, Yen HR, Hsu CH. Utilization and prescription patterns of traditional Chinese medicine for patients with hepatitis $\mathrm{C}$ in Taiwan: a population-based study. BMC Complement Altern Med. 2016; 16(1):397.

41. Liao YH, Lin CC, Lai HC, Chiang JH, Lin JG, Li TC. Adjunctive traditional Chinese medicine therapy improves survival of liver cancer patients. Liver Int. 2015;35(12):2595-602.

42. Tsai TY, Livneh H, Hung TH, Lin IH, Lu MC, Yeh CC. Associations between prescribed Chinese herbal medicine and risk of hepatocellular carcinoma in patients with chronic hepatitis B: a nationwide population-based cohort study. BMJ Open. 2017;7(1):e014571.

\section{Submit your next manuscript to BioMed Central and we will help you at every step:}

- We accept pre-submission inquiries

- Our selector tool helps you to find the most relevant journal

- We provide round the clock customer support

- Convenient online submission

- Thorough peer review

- Inclusion in PubMed and all major indexing services

- Maximum visibility for your research

Submit your manuscript at www.biomedcentral.com/submit
Biomed Central 